\title{
Science comes second as NASA makes lunar plans
}

WASHINGTON DC

NASA has set a goal of returning astronauts to the Moon in 2018 and begun defining a series of precursor missions for the next decade. But scientists and international partners are wondering how they fit into the plan.

NASA administrator Mike Griffin last week presented a broad outline of the programme, which he estimates will cost $\$ 104$ billion by 2018. On early missions, four astronauts will spend up to seven days on the Moon's surface, twice as long as the Apollo astronauts did. Eventually, crews will spend up to six months at a time living at a lunar outpost.

Long before people arrive, NASA will scout landing sites and do the technical groundwork with orbiting spacecraft and robot landers starting with the Lunar Reconnaissance Orbiter (LRO) in 2008 and a landing mission targeted for sometime between 2009 and 2011.

The LRO, costing $\$ 450$ million to $\$ 500 \mathrm{mil}$ lion, will be among the most capable planetary spacecraft ever built. Six onboard instruments will photograph the Moon and map its topography "at an engineering scale", according to NASA chief scientist James Garvin. Five instruments will try to nail down the presence of water ice in shadowed craters - a critical resource for later human visitors.

Several nations are working on their own scientific missions to the Moon. Europe's SMART-1 probe, which has been in lunar orbit for nearly a year, recently had its mission extended to mid-2006. China, Japan and India plan to send orbiters before the LRO arrives.

But the rapid development of NASA's next two missions rules out international participation for the time being, Mark Borkowski, head of the Robotic Lunar Exploration Program at

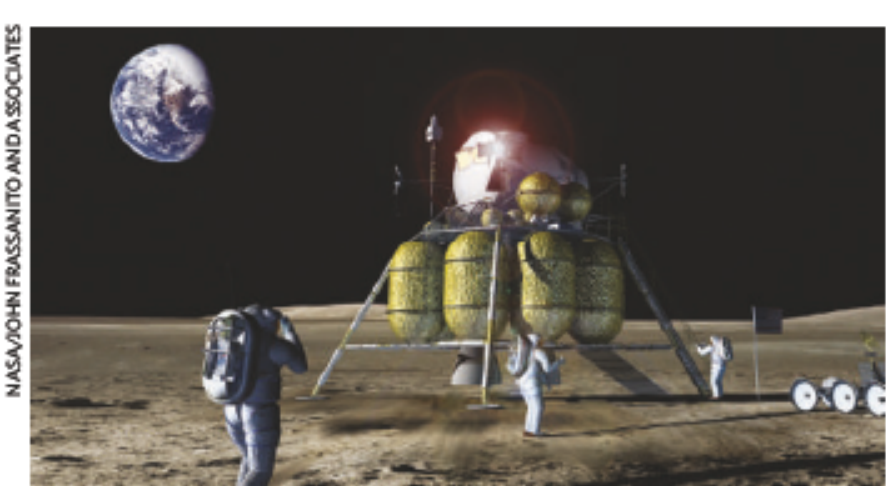

NASA headquarters, told an international lunar-exploration conference last week in Toronto, Canada. "We are frankly disappointed," he said. But in the long run, he promised, "we intend to go to the Moon with you".

Planning for the first landing mission is under way. Teams from five NASA centres have proposed concepts, and the winner will be selected soon, says Borkowski. The lander is likely to be sent wherever the LRO detects ice - probably the south pole. It has yet to be decided whether it will be a $\$ 450$-million lander or a larger $\$ 750$-million version. If the latter, the launch could slip to 2011.

The current focus on hardware and site selection - engineering rather than scienceworries some researchers. "My immediate reaction was: 'So what are they going to do on the Moon? Where's the beef? ${ }^{\text {? }}$ says Wesley Huntress, a former NASA science chief now with the Carnegie Institution of Washington.

"You have to stick up for science all along," adds Jeffrey Taylor, a University of Hawaii planetary scientist. He chairs the Lunar Exploration Analysis Group, set up to give NASA scientific advice on the Moon programme. It is identifying topics, ranging from biology to astronomy, that could form the basis of a research programme run by lunar astronauts or robots once a Moon base is in place.

But it is fine if science doesn't drive the programme, argues Lennard Fisk, a University of Michigan space scientist who chairs the National Academies' Sciences Space Studies Board. NASA has got into trouble by trying to justify projects such as the space station on the basis of science. "I'm relieved that we're not trying to force the science on the Moon," he says. Tony Reich hardt

Getting down to worke but will astronauts on NASA's planned missions be doing useful science?
ON THE RECORD

"We sent authors

$\$ 5$ cheques. One

altered it to $\$ 6,005$

and tried to cash it."

William Gardner, of the University of Pittsburgh, on the fate of money sent to thank participants in astudy of clinicar-trial publication practices.

\section{'If this makes the} climate loonies in the States realize we've got a problem, some good will come out of a truly awful situation."

John Lawton, chaiman of the UK Royal Commission on Environmental Pollution, speaks out on the unusually fierce US hurricaneseason.

Source: The Independent

\section{SCORECARD}

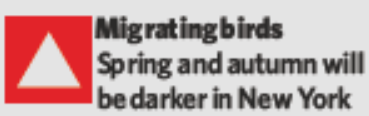

City. To reduce the number of birds hitting skyscrapers, lights above 40 th floors must be turned off at midnightduring migration.

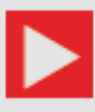

Displaced dolphins

Hur ricane Katrina threw eight trained dolphins

from a Mississippi aquarium into the Gulf of Mexico. Marine biologists have now 'rescued' them back into captivity.

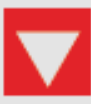
Mosquitoes Scientists are developing a hormone therapy that aims to make mosquitoes urinate themselves todeath.

\section{OVERHYPED}

Missing the win would hurt more How bad is that pain? Medical emergencies aren't sourgent during a major sports event, as research has shown. Now scientists in baseball-crazy Boston have quantified the effect (J. S. Brownsteinetal Ann. Emerg. Med, in the press). During league championships in 2004, when the local Red Sox looked set to lose, emergency-room visits were $15 \%$ higher thanexpected during such an event By the time the Sox were winning the World Series (the first time since 1918), visits fell to $15 \%$ fewer than expected. 